\title{
Profile of congenital heart disease and access to definitive care among children seen at Gulu Regional Referral Hospital in Northern Uganda: a four-year experience
}

Twalib Aliku", Andrea Beaton², Sulaiman Lubega', Alyssa Dewyer ${ }^{3}$, Amy Scheel$^{4}$, Jenipher Kamarembo ${ }^{5}$, Rose Akech ${ }^{5}$, Craig Sable ${ }^{2}$ and Peter Lwabi ${ }^{1}$

\begin{abstract}
Objectives: The aim of this study was to describe the profile of Congenital Heart Disease [CHD] and access to definitive surgical or catheter-based care among children attending a regional referral hospital in Northern Uganda.

Methods: This was a retrospective chart review of all children aged less than 17 years attending Gulu Regional Referral Hospital Cardiac clinic from November 2013 to July 2017.

Results: A total of 295 children were diagnosed with CHD during the study period. The median age at initial diagnosis was 12 months [IQR: 4-48]. Females comprised 59.3\% [ $n=175]$ of cases. Diagnosis in the neonatal period accounted for only $7.5 \%$ [ $n=22]$ of cases. The commonest CHD seen was ventricular septal defect [VSD] in $19.7 \%$ [ $n=58$ ] of cases, followed by atrioventricular septal defect (AVSD) in $17.3 \%$ [ $n=51]$ and patent ductus arteriosus (PDA) in $15.9 \%[n=47]$. The commonest cyanotic CHD seen was tetralogy of Fallot [TOF] in $5.1 \%[n=$ 15], followed by double outlet right ventricle [DORV] in $4.1 \%[n=12]$ and truncus arteriosus in $3.4 \%[n=10]$. Dextro-transposition of the great arteries [D-TGA] was seen in $1.3 \%$ [ $n=4]$. At initial evaluation, $76 \%$ [n=224] of all CHD cases needed definitive intervention and $14 \%$ of these children [ $n=32]$ had accessed surgical or catheterbased therapy within 2 years of diagnosis. Three quarters of the cases who had intervention $[n=24]$ had definitive care at the Uganda Heart Institute (UHI), including all 12 cases who underwent catheter-based interventions. No mortalities were reported in the immediate post-operative period and in the first annual follow up in all cases who had intervention.

Conclusions: There is delayed diagnosis of most rural Ugandan Children with CHD and access to definitive care is severely limited. The commonest CHD seen was VSD followed by AVSD. The majority of patients who had definitive surgery or transcatheter intervention received care in Uganda.
\end{abstract}

Keywords: Congenital Heart Disease, Profile, Gulu, Access to Care

\footnotetext{
* Correspondence: twalib90@gmail.com

'Division of Paediatric cardiology, Heart Institute, Mulago Hospital Complex, Kampala, Uganda

Full list of author information is available at the end of the article
}

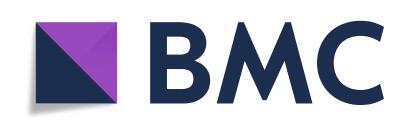

(- The Author(s). 2021 Open Access This article is licensed under a Creative Commons Attribution 4.0 International License, which permits use, sharing, adaptation, distribution and reproduction in any medium or format, as long as you give appropriate credit to the original author(s) and the source, provide a link to the Creative Commons licence, and indicate if changes were made. The images or other third party material in this article are included in the article's Creative Commons licence, unless indicated otherwise in a credit line to the material. If material is not included in the article's Creative Commons licence and your intended use is not permitted by statutory regulation or exceeds the permitted use, you will need to obtain permission directly from the copyright holder. To view a copy of this licence, visit http://creativecommons.org/licenses/by/4.0/. The Creative Commons Public Domain Dedication waiver (http://creativecommons.org/publicdomain/zero/1.0/) applies to the data made available in this article, unless otherwise stated in a credit line to the data. 


\section{Background}

Globally there has been considerable progress in child survival, and millions of children born today have better survival than in 1990, with worldwide mortality rates falling to 39 per 1,000 live births in 2017 compared to 93 per 1,000 live births in 1990 [1]. It is estimated that in the period between 2000 and 2017 , an annual reduction in child mortality rates of $4.2 \%$ was registered in sub-Saharan Africa [1]. This was possible largely due to considerable investments in public health interventions targeting common childhood illnesses such as vaccination programs, treatment of infectious diseases, and ensuring access to clean water and sanitation among others [1].

However, the story for children born with congenital heart disease [CHD] is different. As preventable communicable diseases decline, there is unmasking of the high proportionate burden of CHD as a contributor to infant mortality. With rising populations and high total fertility rates among women in sub-Saharan African countries, there are rising numbers of children born and or living with CHD in these countries. Lower levels of literacy, poor governance and inadequate financial and skilled human resources for health pose considerable challenges in the implementation of possible interventions to reduce the burden of CHD in these countries.

Without early recognition, definitive diagnosis and treatment, it estimated that from one-third to more than half of all children born with significant CHD in developing countries will die in the first month of life [2], while the surviving half will die before their first birth day, making early diagnosis of critical importance. Unfortunately, there are generally few sub-specialist tertiary level pediatric cardiac care services in developing countries, and when available in a country these are often located in the big cities as is the case in Uganda. Fetal cardiology services are virtually non-existent in Uganda, with only very few private facilities within the capital Kampala and the Uganda Heart Institute (UHI) able to offer fetal echocardiography screening. Because of all the foregoing reasons , many descriptive studies on the burden of CHD in subSaharan African countries are limited to data obtained from larger tertiary level health facilities located within the big cities. Furthermore, because of these inequalities in access to pediatric care at regional and district levels, many more rural children with heart disease suffer death or disability compared to those living near cities, often presenting late at initial diagnosis with complications such as failure to thrive, heart failure, infective endocarditis and pulmonary arterial hypertension $[2,3]$.

The aim of this study was to describe the profile of CHD and access to definitive surgical or catheter-based care among children attending a regional referral hospital in Northern Uganda.

\section{Methods}

In September 2013 a satellite cardiac clinic was established at Gulu Regional Referral Hospital (GRRH) in Gulu, in northern Uganda (see Fig. 1). This is a semiurban town located $335 \mathrm{~km}$ from the capital Kampala, serving as a referral point for patients with heart disease in the entire Northern Region of the country that was ravaged by a two-decade civil war. The clinic was open for patient consultations for three working days each week and was staffed with a paediatric cardiologist and two nurses. While this satellite clinic is the only facility providing advanced echocardiographic assessments in the region, a sonographer with general ultrasound skills at the neighbouring St Mary's Hospital, Lacor, located about three miles from GRRH also performs transthoracic echos [TTE] and refers children with suspected heart disease to the cardiac clinic at GRRH.

This was a retrospective chart review. Clinical notes and echocardiographic records of all children diagnosed with CHD aged less than 17 years attending GRRH Cardiac clinic from November 2013 to July 2017 were reviewed. All TTE were performed by a pediatric cardiologist using a portable Vivid Q echocardiography machine [GE Ultrasound, Milwaukee, Wisconsin]. Complex and difficult cases were discussed with other pediatric cardiologists at the Uganda Heart Institute [UHI] located in the capital Kampala or from Children's National Health System [USA]. Need for definitive surgery or cardiac catheterization was assessed using established consensus guidelines [4]. Definitive surgical or catheterbased care was either performed at the UHI [ the only tertiary facility offering advanced cardiovascular care in the country] or abroad.

\section{Results}

A total of 888 children attended the cardiac clinic during the study period (see Fig. 2). Of these, $33.2 \%$ [ $n=295]$ had CHD, whereas $36.6 \%$ were normal $[n=325]$ and $30.2 \%$ [ $n=268$ ] had acquired heart disease [Rheumatic

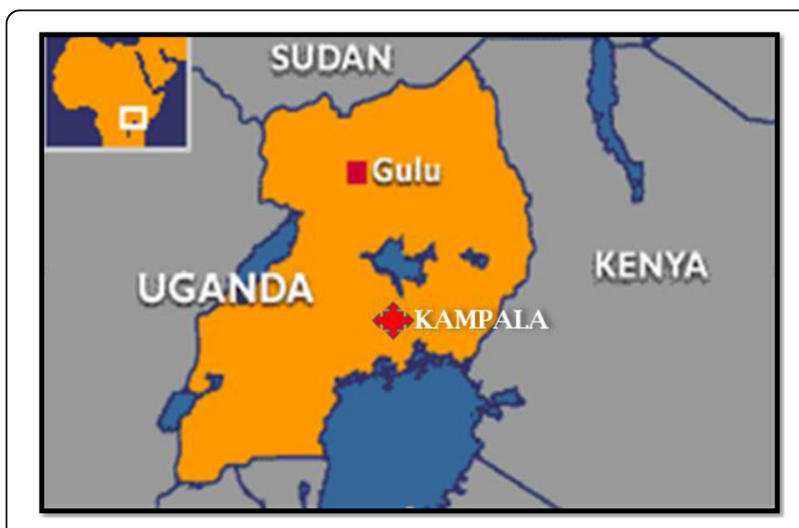

Fig. 1 Location of Gulu in Northern Uganda Where Study was done 


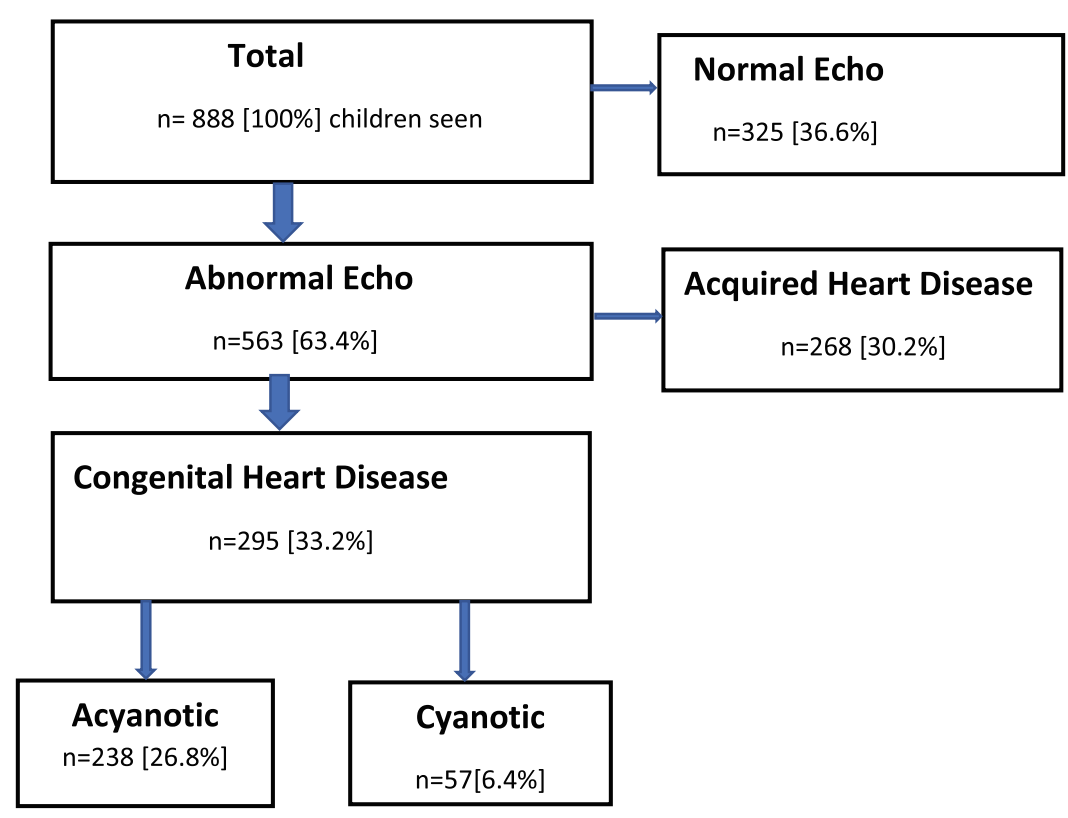

Note: Rheumatic Heart Disease [ $n=220]$ comprised most cases of acquired heart disease, followed by Dilated cardiomyopathy [ $n=22]$. Isolated bilateral superior venacava (SVC) with persistent left SVC draining to coronary sinus were seen in 4 cases and these were classified as normal

Fig. 2 Study Profile. Note: Rheumatic Heart Disease [ $n=220]$ comprised most cases of acquired heart disease, followed by Dilated cardiomyopathy $[n=22]$. Isolated bilateral superior venacava (SVC) with persistent left SVC draining to coronary sinus were seen in 4 cases and these were classified as normal

Heart Disease, RHD; $n=220$ and Dilated Cardiomyopathy, DCMP; $n=22$ ]. The majority of children with RHD were diagnosed through a school-based screening program [5]. Females represented $59.3 \%[n=175]$ of cases with CHD. The median age at diagnosis for patients with CHD was 12 months [QR: 4.0-48]. The median age of cases with acyanotic CHD was 15 months [IQR:5.0-58] while that of cases with cyanotic CHD was 10 months [IQR:3.5-43]. Neonates [children aged $<28$ days] comprised only $7.5 \%$ [ $n=22]$ of cases, with infants [children aged 1-12 months] representing most cases at $42.4 \%$ [ $n=125]$, (see Table 1). None of the cases had prior prenatal diagnosis.

Acyanotic CHD comprised of $80.7 \%$ of all cases of CHD. The commonest CHD seen was ventricular septal defect [VSD] in $19.7 \%$ [ $n=58]$ of cases (see Table 2), followed by atrioventricular septal defect [AVSD] in $17.3 \%[n=51]$ and patent ductus arteriosus (PDA) in $15.9 \%$ [ $n=47]$. Complete AVSD was the commonest subtype of AVSD seen [complete, $n=45$; transitional, $n=1$ and partial, $n=5]$. The clinical phenotype of Down syndrome was identified in 45 of cases with AVSD all of whom had complete AVSD. Isolated atrial septal defects [ASDs] were seen in $10.2 \%$ of cases $[n=30]$ and a patent foramen ovale [PFO] seen in $7.5 \%[n=22]$. Obstructive lesions were rarely seen, with pulmonic stenosis seen in $3.7 \%[n=11]$ and coarctation of the aorta in $1 \%[n=3]$.

The commonest cyanotic heart diseases seen was tetralogy of Fallot [TOF] in 5.1\% [ $n=15]$ of CHD cases, followed by double outlet right ventricle [DORV] in $4.1 \%[n=12]$ and truncus arteriosus (TA) in $3.4 \%$

Table 1 Baseline Characteristics in patients with CHD, Total $N=$ 295

\begin{tabular}{ll}
\hline Variable & Number (\%) \\
\hline Gender, Female & $175(59.3 \%)$ \\
Median age at diagnosis (IQR), months & $12(4-48)$ \\
Age Category at initial diagnosis & \\
Neonates (0-28 days) & $22(7.5 \%)$ \\
Infants (1-12 months) & $125(42.4 \%)$ \\
Young child (1-5years) & $81(27.5 \%)$ \\
Older Child (6-17years) & $67(22.7 \%)$ \\
CHD Type & \\
Acyanotic CHD & $238(80.7 \%)$ \\
Cyanotic CHD & $57(19.3 \%)$ \\
\hline
\end{tabular}

The median age of cases with Acyanotic CHD was 15 months (IQR:5-60) The median age of cases with cyanotic CHD was 10 months (IQR:3.5-43) 
Table 2 Distribution of Acyanotic CHD $(N=238)$

\begin{tabular}{ll}
\hline Type of Lesion & $\begin{array}{l}\mathbf{N} \text { (Percentage of } \\
\text { Total CHD, } \boldsymbol{n = 2 9 5} \text { ) }\end{array}$ \\
\hline Ventricular septal defect (VSD) & $58(19.7 \%)$ \\
Patent Ductus Arteriosus (PDA) & $47(15.9 \%)$ \\
Atrial septal defects (ASD) & $30(10.2 \%)$ \\
Atrioventricular septal defects (AVSD) & $51(17.3 \%)$ \\
Pulmonary stenosis (PS) & $11(3.7 \%)$ \\
Bicuspid aortic valve (BAV) & $4(1.4 \%)$ \\
Coarctation of Aorta (COA) & $3(1.0 \%)$ \\
Others & $34(11.5 \%)$ \\
Total & $\mathbf{2 3 8}(\mathbf{8 0 . 7} \%)$
\end{tabular}

Note: Others included defects such as patent foramen ovale $(n=22)$, among other defects

$[n=10]$, see Table 3. Cases of dextro-transposition of the great arteries (d-TGA) was seen in $1.3 \%[n=4]$. During the study only $1 \%[n=3]$ of cases with critical duct dependent lesions were seen [one each with d-TGA with intact ventricular septum, pulmonary atresia with intact ventricular septum and hypoplastic left heart syndrome].

At initial evaluation, 76\% [ $n=224]$ of all CHD cases needed definitive intervention, whereas $14 \%[n=40]$ were stable for observation and follow up to determine long-term care plan (see Fig. 3). Unfortunately, $1 \%$ of cases $[n=3$ ] were considered inoperable at initial evaluation [a ten-year-old child with VSD and Eisenmenger syndrome, and two older children having heterotaxy syndrome, complex CHD and severe pulmonary arterial hypertension]. During the study period, $14 \%$ of children $[n=32]$ in need of definitive intervention had accessed surgical or catheter-based therapy. Three quarters of the cases who had access to surgical or transcatheter therapy $[n=24]$ had definitive care at the UHI including all 12 cases who underwent catheter-based interventions [PDA

Table 3 Distribution of cyanotic CHD

\begin{tabular}{ll}
\hline Type of Lesion & $\begin{array}{l}\text { N (Percentage of Total } \\
\text { CHD, } \boldsymbol{n = 2 9 5 )}\end{array}$ \\
\hline Tetralogy of Fallot (TOF) & $15(5.1 \%)$ \\
Double Outlet RV (DORV) & $12(4.1 \%)$ \\
Truncus arteriosus (TA) & $10(3.4 \%)$ \\
d-Transposition of the Great Arteries (d-TGA) & $4(1.3 \%)$ \\
Tricuspid Atresia & $5(1.7 \%)$ \\
Pulmonary atresia (With one case having & $5(1.7 \%)$ \\
intact ventricular septum & \\
Others & $6(2.0 \%)$ \\
Total & $\mathbf{5 7}(\mathbf{1 9 . 3} \%)$
\end{tabular}

Others included Double inlet left ventricle $(n=2)$, Hypoplastic Left heart syndrome $(n=1)$, Ebstein's anomaly $(n=1)$, A univentricular heart of RV morphology with pulmonary atresia $(n=1)$ and a case of left atrial isomerism with common atrium, double out RV and malposed great arteries

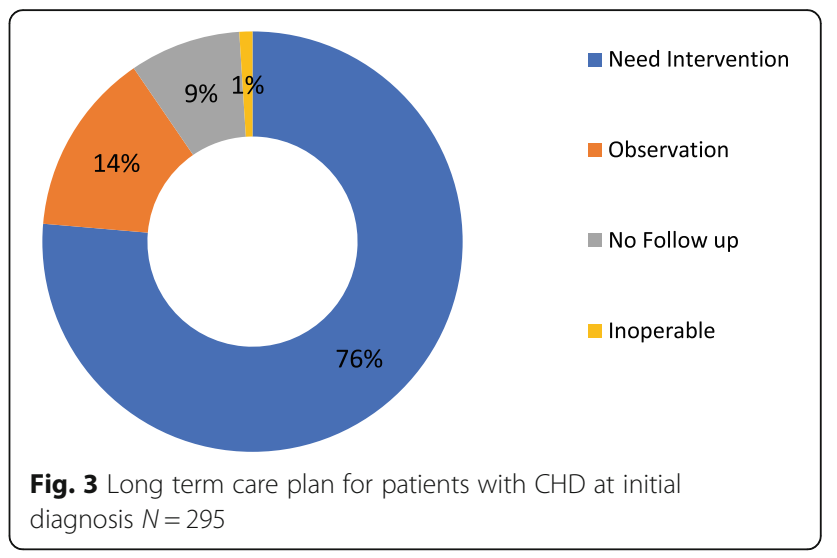

device occlusion/coil embolization, $n=11$ and balloon pulmonary valvuloplasty, $n=1]$. The catheterization team at the UHI performed all the interventions independently. The cases who underwent surgical care at the UHI included lower risk procedures such as ASD closure $[n=5]$, PDA ligation $[n=4]$, coarctation of aorta repair $[n=1]$, VSD closure $[n=1]$ and TOF repair $[n=1]$. The surgical team at the UHI independently operated on all cases done locally except for 3 ASD cases which were done during surgical camps organized with visiting surgical teams. The local teams combined (both catheterization and surgical) independently performed $87.5 \%[n=21]$ of the cases done locally. The remaining 8 cases obtained definitive surgical care from abroad [VSD closure $=5$, ASD closure $=1$ and DORV + PS $=$ 1]. The operations done outside Uganda took place in Germany $[n=1$, the case with DORV $+\mathrm{PS}]$, Cayman Islands $[n=1$, a case with VSD] and the rest were performed in India $[n=5]$. The cases operated abroad were all funded through charity organizations, except a case of a VSD performed in India were the parents raised funds from family and friends.

Open Heart Surgery at the UHI costs $\$ 5000$, and closed heart procedures, including transcatheter interventions cost $\$ 950$ for citizens. All cases who had definitive surgical or transcatheter care at the UHI were sponsored by grants from charity organizations, except in one case [coarctation of the aorta repair that was further subsidized by the UHI and the family paid \$550]. In two cases, parents declined surgery or transcatheter therapy when they were offered opportunity despite counselling. These included the case of a 15-year-old athletic girl diagnosed with a large secundum ASD through a school based RHD screening program and another case of a 7-year-old girl with a large PDA whose single mother could not find an adult relative to look after 3 younger siblings during a proposed hospitalization for PDA device closure.

No mortalities were reported in the immediate postoperative period and in the first annual follow up in all cases who had intervention. At the last scheduled follow- 
up in March 2019 [median follow up period of 38 months, range 15-58 months], there were no deaths recorded but morbidities were noted in two cases. A patient who underwent PDA ligation in infancy had transcatheter closure of a small residual PDA shunt at the age of two years [both procedures were performed at the UHI]. A 15-year-old boy status post secundum ASD repair developed myocarditis and subsequent dilated cardiomyopathy with severe left ventricular dysfunction 18 months following surgery. $\mathrm{He}$ remains on heart failure medicines with New York Heart Association stage II heart failure symptoms.

\section{Discussion}

In this retrospective review, we have characterized the profile of CHD in a regional referral hospital in Northern Uganda. We found evidence of delayed access to initial diagnosis for CHD, with only $7.5 \%$ of patients diagnosed in the neonatal period. The median age at diagnosis of 12 months seen in this study is substantially longer than the mean age of 5 months reported by Namuyonga et al. [6] observed in the Capital Kampala and likely reflects poor screening at lower-level health facilities and weak health system referral infrastructure within the catchment area of GRRH. These findings of delayed CHD diagnosis in a developing country contrast routine fetal and neonatal diagnosis in developed countries [7] and may explain a shift in the epidemiological profile of CHD observed in developing countries, secondary to natural selection.

As demonstrated around the world [6, 8-12], VSDs were the commonest forms of CHD diagnosed in Northern Uganda. The peculiar finding in this study was the high number of cases of AVSD seen, accounting for $17.3 \%$, whereas most studies from Africa report prevalence of AVSD between 5 and $8 \%$ of total CHD $[9,11]$. As expected, most patients with AVSD in this study had the clinical phenotype of Down's syndrome [representing $90 \%$ or $45 / 51$ cases of AVSD] which is similar to that found by Chelo et al. in Cameroon [9] who reported that $80 \%$ of cases of AVSD had Down's syndrome. While the high representation of AVSD in this study is surprising, it could be explained by the possible selection bias where prior echocardiographic screening in a neighbouring hospital may have resulted in referral of more obvious forms of CHD.

Like it has been previously reported elsewhere in the country [13], a relatively high number of children with truncus arteriosus were seen in this series accounting for $3.4 \%[n=10]$ of total CHD cases. This may be explained by a better early survival advantage of truncus arteriosus cases compared with other critical duct dependent lesions, or yet to be determined genetic factors. The low numbers of cases with critical disease in this series [such as D-TGA, $n=4$ and other duct dependent defects $n=$
3] which are usually diagnosed in the newborn period, are likely attributable to early neonatal death before referral for diagnostic evaluation. Prostaglandin E to maintain ductal patency has only recently become available in the country and can only be accessed from private pharmacies in the capital Kampala. In this study only three patients were deemed inoperable at index evaluation.

Timely access to initial diagnosis followed by definitive surgical or catheter based cardiac interventions is critical to optimize survival and quality of life for children with significant CHD [14, 15]. When available in a developing country, these advanced cardiac interventions remain of limited scope because of financial and human resource constraints. In this study, $76 \%$ of children with CHD needed definitive intervention at initial presentation, and only $14 \%$ of those were able to access definitive surgical or catheter-based therapy within two years of diagnosis. While the $14 \%$ access to definitive therapy for CHD in this study is better than the $9 \%$ [49/502] access to definitive surgical care for patients in the Ugandan RHD registry [16], this study highlights the huge need for advanced tertiary level cardiac care services for patients with heart disease in Uganda.

It is estimated that 9 out of every 10 people living in low- and middle-income countries [currently comprising nearly 6 billion of the world's population], lack access to cardiac surgical care when needed due to geographic, infrastructure, quality, and financial barriers [17-19]. The favorable safety and cost-effectiveness of providing cardiac surgical care in low- and middle-income countries is increasingly being recognized [20-22]. As demonstrated in this study, in which three quarters of definitive procedures were performed locally at the UHI [24 of 32 cases who underwent surgical or catheter-based therapy], with $87.5 \%$ of all procedures carried out independently by the local team, developing in-country capacity to deliver tertiary level care for children with CHD remains the best approach to increase access to definitive congenital heart disease care in developing countries. Over the past decade the UHI through its partnerships has invested heavily in building local capacity to perform lifesaving procedures in country, with remarkable progress [23-25].

\section{Conclusions}

There is considerable delay in the initial diagnosis of CHD in our series with less than $10 \%$ of children receiving neonatal diagnosis. An unusually high proportion of AVSD was represented in this series, and these cases were majorly associated with Down Syndrome. A relatively high number of cases with truncus arteriosus were observed as well, where as critical duct -dependent lesions were rarely seen (probably related to lack of identification and early mortality in the newborn period). There is need to increase newborn screening in 
peripheral or regional hospitals in developing countries for early identification and referral of children with suspected CHD through measures such as pulse oximetry screening. Increasing local national capacity for incountry repair of the commonest forms of CHD is essential to increase access to definitive care in those needing intervention.

\section{Abbreviations}

ASD: Atrial septal defect; CHD: Congenital heart disease; DORV: Double outlet right ventricle; PDA: Patent ductus arteriosus; TOF: Tetralogy of Fallot; TA: Truncus arteriosus; UHI: Uganda Heart Institute; VSD: Ventricular septal defect

\section{Acknowledgements}

We are grateful to several charity organizations that offered to fund surgeries and transcatheter procedures for patients in the study.

\section{Authors' contributions}

TA provided major contributions in concept, review design, data collection, literature review and drafting the manuscript. $A S, A D, J K$ and RA contributed to data collection, clinical care and manuscript review. AB, CS, SL and PL contributed to concept, study design, clinical care of cases and manuscript review. All authors read and approved the final manuscript.

\section{Funding}

Clinical care for patients was possible through part funding provided by Gift of Life International, Edwards Life sciences and Uganda Heart Institute.

\section{Availability of data and materials}

The data sets analyzed during the current study are available from the corresponding author upon reasonable request.

\section{Declarations}

\section{Ethics approval}

The study was approved by the Makerere University School of Medicine Research Ethics Committee as part of a school based Rheumatic Heart Disease screening project.

\section{Consent for publication}

Not applicable.

\section{Competing interests}

The authors declare that they have no competing interests.

\section{Author details}

${ }^{1}$ Division of Paediatric cardiology, Heart Institute, Mulago Hospital Complex, Kampala, Uganda. ${ }^{2}$ Cincinnati Children's Hospital Medical Center, Cincinnati, $\mathrm{OH}$, USA. ${ }^{3}$ Children's National Health System, Washington, DC, USA. ${ }^{4}$ Emory University school of Medicine, Atlanta, GA, USA. ${ }^{5}$ Gulu Regional Referral Hospital, Gulu, Uganda.

Received: 22 December 2020 Accepted: 5 May 2021

Published online: 24 May 2021

\section{References}

1. UN Inter-Agency Group for Child Mortality Estimation. Levels and Trends in Child Mortality Report for 2018. UNICEF. NEW YORK. Available online at www.unicef.org > UN-IGME-Child-Mortality-Report-2018. Accessed 18 December 2020.

2. Thakur JS, Negi PC, Ahluwalia SK, Sharma R. Integrated community-based screening for cardiovascular diseases of childhood. World Health Forum. 1997:18:24-7.

3. Hewitson J, Brink J, Zilla P. The Challenge of Pediatric Cardiac Services in the Developing World. Semin Thorac Cardiovasc Surg. 2002;14(4):340-5.

4. Saxena A, Ramakrishnan S, Tandon R, Shrivastava S, Ahamad Z, et al Consensus on timing of intervention for common congenital heart disease. Indian Pediatr. 2008 Feb;45(2):117-26.
5. Beaton A, Lu JC, Aliku A, Dean P, Gaur L, Weinberg J, et al. The utility of handheld echocardiography for early rheumatic heart disease diagnosis: a field study. European Heart Journal - Cardiovascular Imaging Jan. 2015. doi: https://doi.org/10.1093/ehjci/jeu296.

6. Namuyonga J, Lubega S, Aliku A, Omagino J, Sable C, Lwabi P. Pattern of congenital heart disease among children presenting to the Uganda Heart Institute, Mulago Hospital: a 7-year review. African Health Sciences. 2020; 20(4):745-52.

7. Mocumbi AO, Lameira E, Yaksh A, Paul L, Ferreira MB, et al. Challenges on the management of congenital heart disease in developing countries. Int J Cardiol. 2011:148(3):285-8.

8. Nampijja D, Kumbakumba E, Bajunirwe F, Mondo C. Burden of Heart Diseases in Children attending cardiology clinic in a regional referral hospital in Uganda. Int Clin Pathol J. 2017;4(4):00102.

9. Abqaari S, Gupta A, Shahab T, Rabbani MU, Ali SM, Firdaus U. Profile and risk factors of congenital heart defects: A Study in a Tertiary Care Hospital. Ann Pediatr Card. 2016:9:216-21.

10. Haq FU, Jalil F, Hashmi S, Jumani MI, Imdad A, Jabeen M, et al. Risk factors predisposing to congenital heart defects. Ann Pediatr Cardi. 2011:4(2):117-21.

11. Chelo D, Nguefack F, Menanga AP, Ngo Um S, Gody JC, Tatah SA, Koki Ndombo PO. Spectrum of heart diseases in children: an echocardiographic study of 1666 subjects in a pediatric hospital, Yaounde, Cameroon. Cardiovasc Diagn Ther. 2015. doi:https://doi.org/10.3978/j.issn.2223-3652.2015.11.04.

12. Massoure P, Roche N, Lamblin G, Dehan C, Kaiser E, Fourcade L. Cardiovascular disease in children in Djibouti: a single-centre study. Pan African Medical Journal. 2013;14:141. doi:.

13. Sani M, Mukhtar-Yola M, Karaye K. Spectrum of Congenital Heart Disease in a Tropical Environment: An Echocardiography Study. J Natl Med Assoc. 2007;99(6):665-9.

14. Brown KL, Ridout DA, Hoskote A, Verhulst L, Ricci M, Bull C. Delayed diagnosis of congenital heart disease worsens preoperative condition and outcome of surgery in neonates. Heart. 2006;92:1298-302.

15. Peterson C, Dawson A, Glidewell J, Garg LF, Braun KVN, Knapp MM, et al. Hospitalizations, costs, and mortality among infants with critical congenital heart disease: How important is timely detection? Birth Defects Res A Clin Mol Teratol. 2013;97:664-72.

16. Zhang W, Okello E, Nyakoojo W, Lwabi P, Mondo CK. Proportion of patients in the Uganda rheumatic heart disease registry with advanced disease requiring urgent surgical interventions. African Health Sciences. 2015;15(4):1182-8.

17. Neirotti R. Paediatric Cardiac Surgery in less privileged parts of the world. Cardiol Young. 2004;14:341-6.

18. Vervoot D. The neglected component of cardiovascular care: dispelling the myths. Global Heart. 2019;14(3):281-3.

19. Vervoort D, Swain JD, Pezzella AT, Kpodonu J. Cardiac Surgery in Low- and Middle-Income Countries: A State-of-the-Art Review. Ann Thorac Surg. 2020 Aug 6:S0003-4975(20)31293-5. doi: https://doi.org/10.1016/j.athoracsur.2020.05.181].

20. Cardarelli M, Vaikunth S, Mills K, et al. Cost-effectiveness of Humanitarian Pediatric Cardiac Surgery Programs in Low- and Middle-Income Countries. JAMA Netw Open. 2018;1:e184707.

21. El Rassi I, Assy J, Arabi M, et al. Establishing a High-Quality Congenital Cardiac Surgery Program in a Developing Country: Lessons Learned. Frontiers in Paediatrics. DOl: https://doi.org/10.3389/fped.2020.00357.

22. Larrazabal LA, Jenkins KJ, Gauvreau K, Vida VL, Benavidez OJ, et al. Improvement in Congenital Heart Surgery in a developing country. The Guatemalan Experience Circulation. 2007:116:1882-7.

23. Aliku TO, Lubega S, Lwabi P, Oketcho M, Omagino JO, Mwambu T. Outcome of patients undergoing open heart surgery at the Uganda heart institute, Mulago hospital complex. African Health Sciences. 2014;14(4):946-53.

24. Aliku TO, Lubega S, Namuyonga J, Sable C, Omagino OO, Lwabi P. Pediatric cardiovascular care in Uganda: current status, challenges, and opportunities for the future. Ann Pediatr Cardiol. 2017;10:50-7.

25. Rwebembera J, Aliku T, Kayima J, Lubega S, et al. Starting and Operating a Public Cardiac Catheterization Laboratory in a Low Resource Setting: The Eight- Year Story of the Uganda Heart Institute Catheter Laboratory. Global Heart. 2021;16(1):11. DOl:https://doi.org/10.5334/gh.859.

\section{Publisher's Note}

Springer Nature remains neutral with regard to jurisdictional claims in published maps and institutional affiliations. 